\title{
Searching for XYY Males Through Electrocardiograms
}

\author{
ANGELA M. VIANNA, OSWALDO FROTA-PESSOA, MARCOS F. LION, and \\ LUIS DECOURT
}

\section{From the Laboratory of Human Genetics, Department of Biology, Universidade de São Paulo, Hospital do Servidor Publico do Estado de São Paulo, and the Department of Medicine (II Division), Faculdade de Medicina da Universidade de São Paulo, São Paulo, Brazil}

Price (1968) found that $30 \%$ of 20 males with 47,XYY karyotype had electrocardiograms (ECG) with prolonged $P-R$ intervals. This prompted us to try to ascertain double-Y males by screening a large sample of clinically normal males through their ECG.

From a file of about 30,000 ECGs, collected by one of us (M.F.L.) during the last 7 years, 34 were selected because (1) they were normal except for having $P-R$ intervals of 0.2 second or more and (2) they belonged to clinically and radiologically normal adult males of less than 50 years of age, who were not taking any drugs. The karyotypes of 11 of these subjects were studied. One of them (F.N., Fig. 1) had a P-R interval of 0.24 second and a $47, X Y Y$ chromosome complement (in each of the 34 cells studied). This subject is a tall $(192 \mathrm{~cm})$, middle-class married businessman with no criminal record. He has a son and a daughter who are apparently normal. Each of the other 10 subjects in this series showed a 46,XY karyotype. However, 2 of them, with P-R intervals of $0.22 \mathrm{sec}$ (R.S.) and $0.20 \mathrm{sec}$ (M.B.) had an abnormally long $\mathrm{Y}$ chromosome (Figs. $2 a$ and $2 b$ ).

Received 2 December 1971.

* This work was partly supported by the Conselho Nacional de Pesquisas (Proc. 5544/69) and the Universidade Federal da Bahia, Brazil.
Subsequently 3 other males with enlarged P-R intervals selected from a different cardiologic clinic (Dr L. Decourt) were added to our sample, making 14 such individuals in all. One of these was an adult who fulfilled all the conditions listed above. He had a normal karyotype. The others were 2 boys (N.F. aged 9 and N.C. aged 11), with congenital malformations of the heart (pulmonary stenosis and intraventricular communication respectively) not normally associated with an enlarged $P-R$ interval. Their $P-R$ intervals were respectively $0 \cdot 18$ and $0 \cdot 24$ second, considered prolonged for their ages. Both had a 46,XY karyotype with an abnormally long Y chromosome (Figs. 2c and 2d).

Since the frequency of double $\mathrm{Y}$ males is about 2 per 1000 in newborn populations and about $2.5 \%$ among tall men in prisons and mental hospitals (Marinello et al, 1969), the finding of one XYY individual among 14 presenting prolonged $P-R$ intervals is very suggestive of a high association between these 2 abnormalities. This hypothesis derives additional support from the striking finding that 4 other individuals in this small series show apparent structural abnormalities of the $Y$ chromosome. It is probable that the great size of these Y chromosomes does not represent extreme normal variants, but rather results from the presence of duplicated segments.

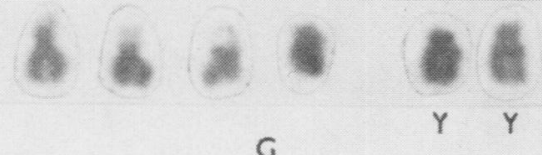

FIG. 1. Karyotype of F.N. (47,XYY). 


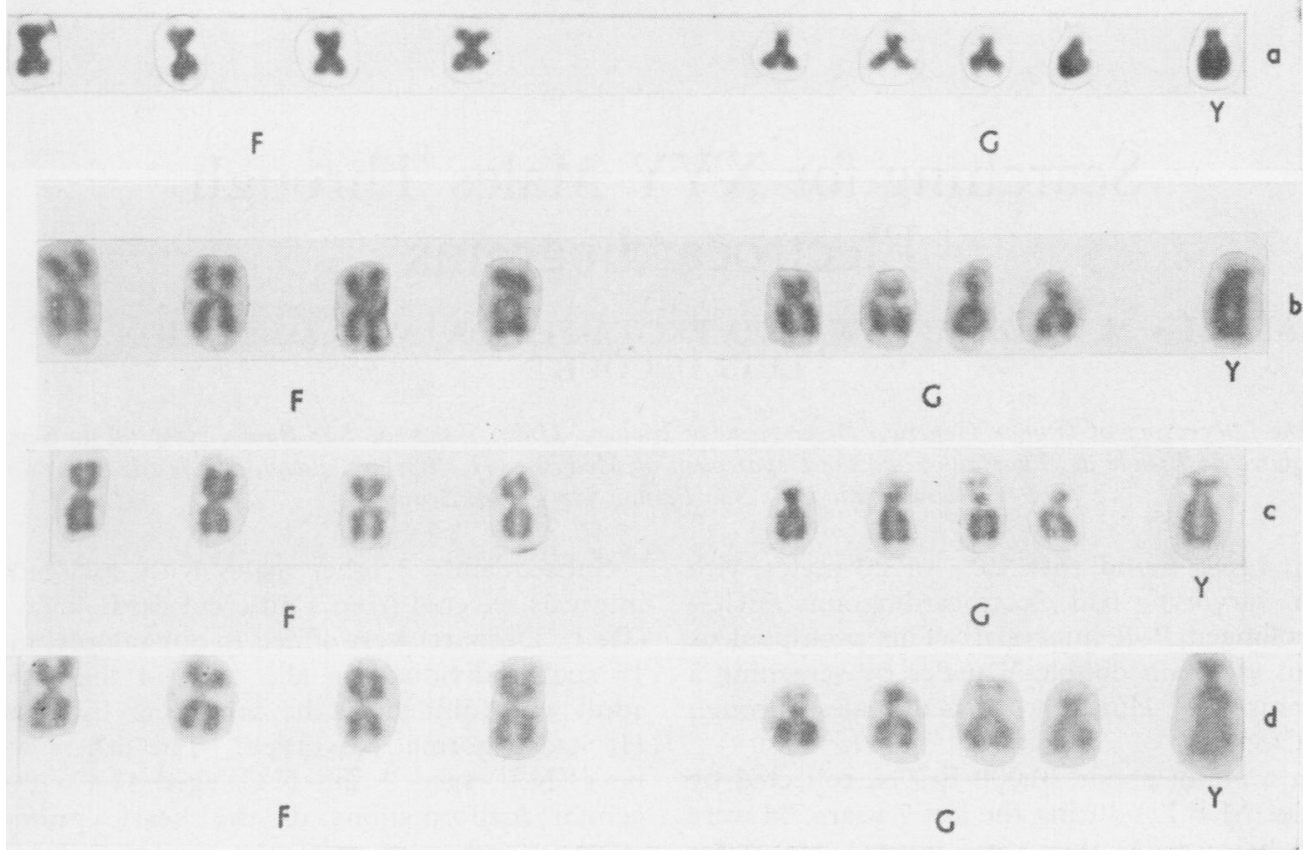

FIG. 2. F and G group chromosomes with a large $Y$ of 4 cases (all 46,XY). (a) R.S., (b) M.B., (c) N.F., and (d) N.C.

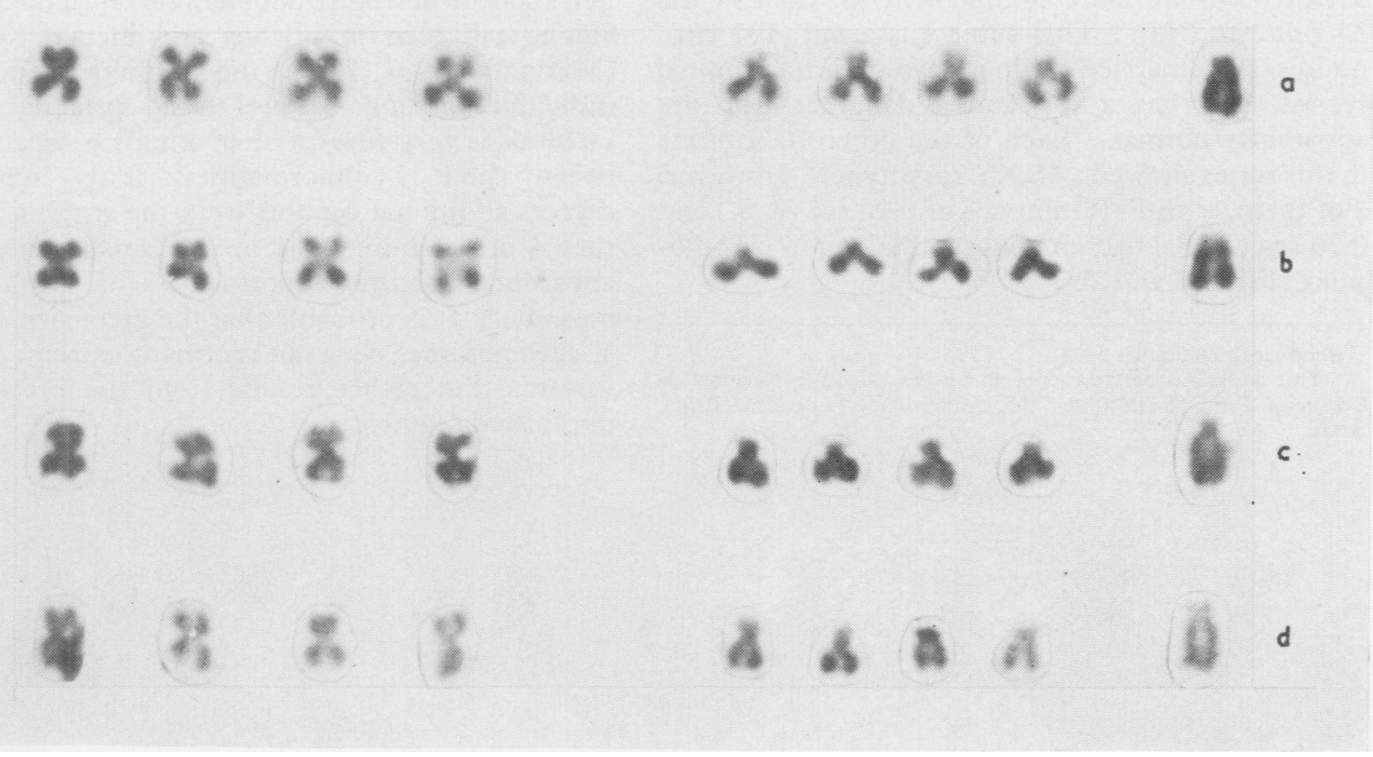

FIc. 3. F and G group chromosomes of male relatives of the propositi. (b) Father L.F. (c), brother E.F., and (d) brother I.F. (a) N.C.'s father; (b) N.F.'s father; (c) N.F.'s brother, (E.F.) ; and (d) N.F's brother (I.F). 
Whatever the exact nature of these abnormalities, the incidence of four individuals with extremely long $\mathrm{Y}$ chromosomes among 14 studied $(28.6 \%)$ is far higher than the $1.5 \%$ found in the general population (Court Brown et al, 1966).

Karyotypic analysis and ECG were performed in the fathers of 2 of the individuals having a large $Y$ chromosome and in 2 brothers of one of these. A long $\mathrm{Y}$ chromosome and normal $\mathrm{P}-\mathrm{R}$ intervals were present in the 4 cases (Fig. 3). This suggests that any association which may exist between a long $\mathrm{Y}$ chromosome and an increased $\mathrm{P}-\mathrm{R}$ interval is far from absolute.

\section{REFERENCES}

Court Brown, W. M., Buckton, K. E., Jacobs, P. A., Tough, I. M., Kuenssberg, E. U., and Knox, J. D. E. (1966). Chromosome Studies on Adults. Cambridge University Press, London.

Marinello, M. J., Berkson, R. A., Edwards, J. A., and Bannerman, R. M. (1969). A study of the XYY syndrome in tall men and juvenile delinquents. Fournal of the American Medical Association, 208, 321-325.

Price, W. H. (1968). The electrocardiogram in males with extra Y chromosomes. Lancet, 1, 1106-1108. 